\title{
Antiestética y la función social del caos en los años sesenta: Luis Felipe Noé como escritor y pintor*
}

ANTIESTÉTICA AND THE SOCIAL FUNCTION OF CHAOS: LUIS FELIPE NOÉ AS

PAINTER AND WRITER IN THE 60 'S

ANTIESTÉTICA E A FUNÇÃO SOCIAL DO CAOS NOS ANOS SESSENTA: LUIS

FELIPE NOÉ COMO ESCRITOR E PINTOR

\section{Juan Camilo Lee Penagos**}

Cuadernos de Música, Artes Visuales y Artes Escénicas

/ Volumen 10 - Número 1 / enero - junio de 2015 /

ISSN 1794-6670/ Bogotá, D.C., Colombia / pp. 165-185

Fecha de recepción: 11 de enero de 2014 | Fecha de aceptación: 10 de marzo 2014 | Disponible en línea: 29 de mayo de 2015. Encuentre este artículo en http:// cuadernosmusicayartes.javeriana.edu.co/ doi:10.11144/Javeriana.mavae10-1.afsc

*Artículo de investigación. Resultado de la tesis del autor para optar a título de Maestro en Historia del Arte en la Universidad Nacional General San Martín de Buenos Aires, Argentina

** Doctorando en Ciencias Sociales y Humanas de la Universidad Nacional de Colombia, Sede Medellín 


\section{Resumen}

En este artículo se analizará el libro Antiestética, publicado por Noé en 1965, en relación con sus pinturas producidas en este mismo periodo. Este libro resume las búsquedas estéticas del joven pintor en su vertiginosa carrera y anticipa las contradicciones que encontrará Noé en su búsqueda creativa durante el siguiente año, cuando deja los pinceles. Tanto en sus textos, como en sus obras se podrán encontrar reflexiones sobre las posibilidades que la pintura, como género artístico, tiene para expresar preocupaciones de índole social. A través de la contextualización de sus obras en el campo artístico argentino del momento y un análisis de las ideas de Antiestética, se presentarán las profundas contradicciones que Noé encontró al buscar una función social para la pintura, al tiempo que una libertad absoluta para el artista.

Palabras clave: arte latinoamericano; pintura; libro de arte; teoría del arte

\section{Abstract}

This article analyzes Antiestética the book published by Luis Felipe Noé in 1965, and its relations with the paintings produced by him in this period. Antiestética resumes the aesthetic searches of this young painter in his vertiginous career, and anticipates the contradictions that Noé will find in his creative research in the next year, when he leaves the brushes. In his texts and works one can find reflections about the possibilities that painting as an artistic genre has to express social concerns. Through the contextualization of his works in the Argentinian artistic field of the moment, and analyzing the ideas of Antiestética, we will present the deep contradictions that Noé found when he searched for a social function for painting at the same time that reclaimed an absolute freedom for the artists.

Keywords: latin american art; painting; art book; art theory

\section{Resumo}

Neste artigo se analisará o livro Antiestética, publicado por Noé nos anos sessenta, em relação às suas pinturas produzidas neste mesmo período. O livro publicado em 1965, Antiestética, resume as procuras estéticas do jovem pintor na sua vertiginosa carreira, e antecipa as contradições que encontrará Noé na sua busca criativa durante o seguinte ano, no momento que deixa os pinceis. Tanto nos seus textos quanto nas suas obras poderão ser encontradas reflexões sobre as possibilidades que a pintura, como gênero artístico, tem para expressar preocupações de índole social. Através da contextualização das suas obras no campo artístico argentino do momento, assim como de uma analise das ideias de Antiestética, serão apresentadas as profundas contradições que Noé achou na procura de uma função social para a pintura, ao mesmo tempo em que achava uma liberdade absoluta para o artista.

Palavras-chave: arte latinoamericano; pintura; livro de arte; teoria da arte 


\section{EL CAOS Y SU LUGAR EN EL MUNDO}

Antiestética se publica en 1965, cuando Noé ya se ha constituido en uno de los pintores jóvenes argentinos más influyentes de esa mitad de decenio. Para esa fecha, Noé ha expuesto en las galerías más renombradas de Buenos Aires, como Bonino y Van Riel, de manera individual y grupal. Ha ganado el premio nacional del certamen organizado por el Instituto Torcuato di Tella en 1963 y una beca del gobierno de Francia. Ha expuesto en el MNBA y ha conocido París y Nueva York. Sin duda, Antiestética manifiesta las reflexiones, dudas, convicciones y retos que este joven porteño ha tenido durante todo ese intenso periodo. En ese libro, Noé expresa varias de las inquietudes que terminaron por caracterizar su propuesta estética, entre ellas la "asunción del caos" y la "visión quebrada". Además, expone una de sus posturas más radicales: la insistencia en la preponderancia absoluta, al interior de las dinámicas del mundo del arte, del proceso creativo por encima de los procesos de recepción de la obra. Noé (1965 [1988]) sostiene que, incluso por encima de la obra misma, el proceso creativo del artista es lo que realmente debería ser valorado en el mundo del arte. La obra debería ser valorada solo en tanto huella del camino que el artista recorre en su búsqueda creativa. Todo aquello que nace de la recepción de la obra, todo aquello que está 'después' de la creación de la misma, como el mercado, la crítica e incluso la enseñanza de arte o la teoría, es secundario al lado de la importancia que Noé atribuye al proceso creativo. Incluso, sostiene que gran parte de esto que sucede después de la creación se vuelve contra ella; son actividades generadoras de prejuicios y obstáculos para el libre desarrollo de las búsquedas artísticas posteriores.

En este libro -y siempre argumentando desde la preponderancia del acontecer creativo por encima del momento de recepción de la obra-, el tema de la nacionalidad del arte ocupa todo un capítulo. Allí, Noé da cuenta de varias de las encrucijadas del medio artístico del momento: la cuestión de la posibilidad de una vanguardia argentina, la manera en que se relacionan la búsqueda de un arte con identidad nacional-que, al mismo tiempo, entre a jugar en la escena internacional-, la crisis del referente europeo para las artes plásticas, la irrupción de Estados Unidos como nuevo modelo y el subdesarrollo cultural de Latinoamérica, entre otros. Como solución final a varias de estas cuestiones, Noé presenta la propuesta creativa que ha terminado por caracterizarlo, esto es, la "asunción del caos" al interior de las obras de arte, entendiendo tal 'caos' como una característica de la realidad latinoamericana y como una propia de ese momento histórico de la cultura occidental:

Nosotros en cambio tenemos la barahúnda de datos aislados de realidades distintas. Tenemos el caos. Se habla de nuestra ausencia de realidad propia. ¿No será ausencia de conciencia de la realidad? También se hablaba de ausencia de realidad respecto a Estados Unidos. A través de sus manifestaciones artísticas este país lo ha desmentido. ¿Cuándo lo haremos nosotros? (Noé, [1965] 1988, p. 175)

Como se verá, Noé muestra la "asunción del caos" por parte del artista latinoamericano como la manera en que el arte de nuestro continente podría entrar a jugar un papel preponderante en el desarrollo mundial de las artes o, en palabras de Noé, del espíritu creador de la época. Aunque no asuma en Antiestética que existe una vanguardia argentina a comienzos de la década del sesenta, Noé afirma en su libro que la exposición del grupo de la Otra Figuración, de 1961, contribuyó a movilizar el medio artístico del momento. Para Noé, tal medio artístico estaba regido por provincialismos y por un "subdesarrollo cultural", que lo único que hacía era 
seguir a destiempo las modas artísticas que provenían de Europa cuando ya estaban vaciadas de vitalidad, o sumirse en referencias folclóricas que cerraban al artista y lo hacían incapaz de asimilarse al proceso creador de la época.

Existía un enorme temor a equivocarse. Pintar era hacer "una obra de arte". Era una gran ceremonia que terminaba en el velatorio de un cadáver. Esto ya no es así. Ya comienza a no tener miedo a equivocarse. Pintar es ya un desencadenamiento vital. Creo que en ese sentido la exposición que nuestro grupo hizo en el año 1962 en la galería Bonino ayudó mucho. De esa falta de temor a equivocarse se ha pasado de inmediato a una convocatoria a la vida que ha irrumpido caóticamente. Esto es lo importante. (Noé, [1965] 1988, p. 188)

La vitalidad y lo caótico aparecen, para la mirada vanguardista de Noé, como indicios de que el panorama artístico porteño empezaba a salir de su ceremonioso letargo. Además, es notable el hecho de que, apenas un par de años después, Noé ya incluye la búsqueda del grupo de la Otra Figuración como un logro histórico en el medio artístico del país. Se pone a la cabeza del proceso de renovación del arte, junto con los demás integrantes de ese grupo.

\section{VANGUARDIA Y REALIDAD}

En la entrevista que concedió Noé para este trabajo, el artista se burlaba un poco de quienes consideraban que la Serie Federal era lo mejor que él había realizado. Se reía de la estupefacción de varios personajes -no daba nombres- ante la calidad de la serie. Lo cierto es que la exposición de 1961 en la galería Bonino de Buenos Aires fue un éxito rotundo en ventas y fue, antes de la exposición de la Otra Figuración, el punto de arranque de su carrera. La Serie Federal se compone de trece telas de corte neofigurativo, donde se tratan temas relacionados directamente con un periodo convulsionado de la historia argentina. A comienzos del siglo XIX, una década después de la Revolución de Mayo, los federales se oponían a los unitarios en relación con la preminencia de la ciudad de Buenos Aires en el contexto nacional. Manuel Dorrego, gobernador federal de la provincia de Buenos Aires en 1828, es asesinado. Juan Manuel de Rosas asume el poder como gobernador de esa provincia y no hay mucha claridad en cuanto a la manera en que la naciente nación argentina será gobernada. Obras como Imagen Agónica de Dorrego (1961), iViva la Santa Federación! (1961), Anarquía del año XX (1961) y Convocatoria a la barbarie (1962), entre otras, hacen parte de esta serie.

La exposición de la Serie Federal en la galería Bonino, en 1961, estaba en sintonía con dos exposiciones de ese mismo año, que también manifiestan una fuerte búsqueda en el lenguaje artístico: Cosas, de Rubén Santantonín en la galería Van Riel, y Arte destructivo, de un grupo de artistas entre los que se cuentan Kenneth Kemble, Jorge López Anaya y Antonio Seguí, en la galería Lirolay. Arte destructivo consistió en un conjunto de materiales y objetos recolectados durante algunos meses antes de la muestra e intervenidos por los artistas de maneras violentas: prendidos en fuego, desgarrados y quebrados. Además, muchos de estos objetos ya se encontraban deteriorados o rotos. Entre estos objetos se encontraban también varias obras de corte informalista, que los mismos autores destruían o manipulaban. Para Giunta (2001, p.141), esta muestra da cuenta de cómo, en las búsquedas artísticas de estos años, se incorporaron materiales que nunca antes habían formado parte del 'sistema' de las artes de la pintura o la escultura. Esos elementos heteróclitos se insertan en las obras, aún más que con el informalismo que, para 1961, ya se había convertido en una tendencia hegemónica. Los 
elementos extra-artísticos -aquellos que remiten a la realidad cotidiana- que el informalismo introdujo en el mundo artístico desde su lugar en la composición de la obra rompían, en Arte destructivo, los límites de la obra, a saber, el espacio que separaba la autorreferencialidad del lenguaje artístico de lo 'real'. Así, lo no-artístico se borraba.

Ahora, por el contrario, el espacio de negociación posible entre autorreferencialidad del lenguaje y heteronomía parecía haberse disuelto ante toda esa colección de desechos desagradables que había invadido la galería. Lo que esta exposición ponía de manifiesto era que el sistema evolutivo del lenguaje, que hasta ese momento había logrado mantenerse asimilando el embate del informalismo, ya no podría recuperarse. (Giunta, 2001, p. 141)

Ese mismo año se realizó la mencionada exposición Cosas de Rubén Santantonín. Construidas con diversos materiales, como tela, cartón o yeso, estas "cosas" colgaban del techo mezclándose en el espacio que recorría el espectador, y aparentaban ser bultos o pelotas mal hechas. De la misma manera que Arte destructivo, las "cosas" de Santantonín abandonan intencionalmente las convenciones de las artes en relación con la organización en disciplinas diferentes, como la pintura y la escultura. Desde el hecho de que no son colgadas en una pared o no reposan sobre un soporte, hasta la evidencia de que son construidas con materiales que no intentan la eternidad, las "cosas" también cuestionan y fuerzan los límites de los códigos artísticos del momento.

Giunta hace también una reflexión sobre el papel que juegan los elementos tradicionalmente extra-artísticos en las búsquedas de los artistas de los sesenta. Enfatiza en la manera en que elementos provenientes de la 'realidad', que antes se consideraban totalmente ajenos al mundo del arte, y también de una 'cultura popular', considerada inferior a la cultura de las galerías y los artistas, empiezan a hacer parte de las búsquedas de estos artistas.

La vanguardia artística se renovaba a partir de la introducción de elementos de la cultura popular. La sintaxis de los objetos, la sorpresa, lo disparatado, la monstruosidad eran rasgos característicos del parque de diversiones. La diferencia es que ahora estos elementos ya no serían reincorporados al sistema sino que sacudirían todos sus fundamentos hasta hacerlos desaparecer. Este quiebre del paradigma modernista va a permitir que una de las líneas de experimentación de los sesenta desplace las reflexiones sobre el lenguaje por las reflexiones sobre la realidad. (Giunta, 2001, p. 142)

Esta reflexión resulta pertinente a la hora de pensar las pinturas de Noé. Si bien la Serie Federal no incluye materiales ajenos al mundo del arte, expresa una búsqueda plástica que incluye cuestiones ajenas a la autonomía artística -como la historia nacional-, sin dejar de lado el interés por crear un arte renovador en términos técnicos y procedimentales. La concurrida frase de Noé al respecto que aparece en Antiestética, en el capítulo sobre la nacionalidad del arte, manifiesta con precisión la función de las cuestiones políticas al interior de las obras de Noé: “La única manera de ser de vanguardia es siendo nacionalista, y la única manera de ser nacionalista es ser de vanguardia" (Noé, [1965] 1988, p. 176).

Así pues, si el intento de artistas como Santantonín o Kenneth Kemble por crear una vanguardia nacional se manifestaba con la inserción de materiales ajenos al mundo artístico, la búsqueda de esa innovación llevó a Noé a tratar las tensiones políticas del país de manera tal que el manejo de los materiales tradicionales expresara también la violencia de esa historia. 
El interés en lo nacional se manifiesta en la representación de esas contradicciones políticas que, con sus tensiones y su caos, terminan por romper desde dentro -de manera vanguardista e innovadora- los preceptos modernistas sobre la pintura. No es una cuestión de forma y contenido: el caos político de la historia de la nación argentina -su realidad- es representado y aludido por el caos vanguardista con el que Noé hace entrar en crisis a la pintura de caballete, para que el arte argentino pueda entrar a jugar un papel preponderante en la historia del arte occidental.

\section{ANTIESTÉTICA Y EL ESPECTADOR AUSENTE}

En Antiestética, Noé enfoca su mirada sobre el estado del mundo del arte contemporáneo en la figura del artista y las relaciones que establece con su medio, su cultura y su obra. Es poco lo que Noé dedica a investigar lo que sucede con el espectador, el crítico, los galeristas y todo aquello que sucede después de la creación de una obra. Y es también poco lo que dedica a pensar, comentar o manifestar sobre los procesos interpretativos que todo espectador debe hacer al experimentar el contacto con una obra. Sin embargo, es mi interés resaltar esta ausencia, por considerarla uno de los ejes principales de las propuestas de Antiestética.

El hecho de que Noé insista de forma tan vehemente en su desinterés por la reacción del público lo coloca en un lugar especial al interior de las discusiones locales, donde gran parte de la búsqueda de los artistas consiste en relacionarse de nuevas maneras con el público. Además, sería imposible explicar del todo la idea de la "asunción del caos" sin tener en cuenta el olvido del espectador: solo a través de este desinterés en el observador de las obras pudo el artista extremar su búsqueda del caos, que para él era nada menos que el rol latinoamericano en la historia del arte occidental. Noé dedica muchas páginas a explicar la labor del artista en términos de intérprete de sí mismo y de su época, a través de una constante búsqueda de lo desconocido. Según el autor, si esta búsqueda es legítima, hará al artista partícipe de un proceso creador histórico; de un espíritu creador que va más allá de las individualidades, que expresa un momento histórico dado y que por ningún motivo debe depender de los procesos de interpretación de las obras:

Aquí se indaga sobre una situación límite en la creación contemporánea. Se trata de un enfrentamiento con el vacío para caer en tierra firme. Este libro está escrito desde adentro mismo del espíritu creador, espíritu que no pertenece ni a mí ni a nadie en particular, sino que me sobrepasa, como sobrepasa a todo individuo; espíritu que es de una época y de una sociedad; espíritu que no tiene detentador alguno. Solo tiene intérpretes. (Noé, [1965] 1988, p. 17)

En Antiestética, Noé afirma que la obra de arte constituye un gran equívoco, puesto que entra en contacto con el espectador: mientras que para el artista la obra es la huella de un complejo y arduo proceso de búsqueda, para el espectador es apenas el comienzo de una nueva experiencia, ya sea como crítico, como curador, o como simple visitante del museo o galería. Esto desemboca en una imposibilidad de comunicación entre el uno y el otro.

Dos años antes de que Antiestética fuera publicado, Umberto Eco dio a luz su libro Obra Abierta. Allí analiza, entre otras, las posibilidades interpretativas que se abren al espectador de la obra de arte contemporáneo. Eco también entiende el caos, el azar y lo indeterminado como signos predominantes de varias esferas de la cultura occidental de esa época, y no solo del arte de los años cincuenta y sesenta. Las disertaciones de Eco empiezan allí donde 
las de Noé terminan, justo en el lugar donde el equívoco comienza: en el encuentro entre el espectador y la obra. Estas dos publicaciones -Obra abierta y Antiestética- abarcan el tema del arte contemporáneo en relación con la necesidad que tiene este de asumir los cambios estructurales de la época, cambios que involucran, según ambos autores, el intento por asir el desorden y el caos.

El texto de Noé no tiene las pretensiones académicas y filosóficas que tiene el de Eco no tendría por qué tenerlas-, pero, aún con sus diferencias, el texto de Eco sirve como marco para desentrañar mejor el sustrato teórico de las propuestas del artista. Al contemplar las posibilidades interpretativas que la obra de arte contemporáneo abre -según Eco- a sus espectadores, y que Noé supone imposibles o inútiles, es posible encontrar explicaciones para el desarrollo que tuvo la obra plástica de este último, en los años subsiguientes.

Publicada en 1965, Antiestética es, por un lado, una suerte de declaración triunfal de un joven artista de ya reconocida trayectoria, con plena conciencia de su importancia en el desarrollo del arte argentino de la época y, por otro, la expresión de la angustia de un pintor que al año siguiente y durante nueve años dejará los pinceles. La crisis que en 1966 lo obliga a dejar de pintar se vincula con la imposibilidad de relacionar su arte con la colectividad y de hacer desaparecer de su obra la marca particular de su individualidad':

La obra individual solo puede dar testimonio de relaciones individuales con el caos. Por lo tanto, además reflejará una coherencia al estar relacionados todos los elementos que integran la obra a un solo sujeto viviente, a una sola voluntad, que se opone a la esencia del caos. (Noé, [1965] 1988, p. 201)

Teniendo en cuenta que es precisamente la relación con el espectador lo que Noé relega en su libro y lo que Eco trabaja en el suyo, se podrá, a través del estudio de las relaciones y los desfases entre las propuestas de ambas publicaciones, encontrar algunas razones que desde ese entonces se estaban gestando para que Noé, en 1966 -después de arrojar a un río buena parte de su obra-, algo más de un año después de publicar Antiestética, dejara de pintar durante casi una década.

Noé hace una distinción muy diciente entre dos miradas posibles hacia el mundo del arte: el arte como resultado y el arte como búsqueda. Ver las obras de arte como resultados-como manifestaciones últimas de un proceso anterior, como cosas valiosas en sí mismas y por sí mismas- produce efectos negativos en el intento que él considera principal para el artista: hacerse partícipe del proceso creador de su época histórica. "El arte como creación es una lucha contra el arte como resultado (Noé, [1965] 1988, p. 61). Como ya se dijo, esto se debe a que la mirada ajena al proceso íntimo del artista, aquella que ve en la obra un resultado y un punto de partida para diferentes actividades -como la crítica, la teoría, el mercado o la enseñanza- no puede tener en cuenta el verdadero intento del artista y sería por ello no solo incapaz de entender lo que se plantea en la obra, generando consecuencias adversas para el libre desarrollo del proceso creativo, sino que también crearía prejuicios, modas y mercados poco alentadores para una búsqueda artística genuina.

No hablo del artista y la obra sino de la obra como límite entre dos fenómenos distintos: el quehacer del artista y el enfrentamiento de todo el mundo frente a su quehacer. Por arte como resultado entiendo todos los epifenómenos de la creación (...) Por arte como resultado entiendo un fenómeno totalmente ajeno a la creación, y que parte del hecho de la obra creada (...) Es 
que si la obra es el punto de separación entre el fenómeno de la creación y los epifenómenos de esta, es porque ella misma es un epifenómeno (...) Y si la obra es el punto de revelación del desencuentro entre el artista y el espectador, en lugar de punto de encuentro, es por un hecho simple. Porque la obra queda como cosa allí y se la toma como un hecho independiente, en consecuencia. (Noé, [1965] 1988, p. 73)

Noé entiende entonces la obra como un punto de encuentro entre distintas miradas sobre el arte, un punto donde el equívoco es ineludible.

Por su lado, Eco, con su concepto de "obra abierta" ([1962] 1985), afirma que el espectador se convierte -en tanto intérprete de la obra de arte- en alguien que hace parte de la creación del significado de la obra. Esta relación de apertura entre la obra y el espectador es de gran importancia en su concepción de arte, pues la posibilidad de mover al espectador a través de diferentes interpretaciones es una de las características que este investigador asigna a toda obra. Esta apertura consciente expresa, para Eco, importantísimos cambios estructurales del momento histórico:

Por ello, no será aventurado encontrar en la poética de la obra "abierta" (y más aun de la obra en movimiento), de la obra que en cada goce no resulta nunca igual a sí misma, las resonancias vagas o precisas de algunas tendencias de la ciencia contemporánea (...) Bien podría pensarse que esta fuga de la necesidad segura y sólida y esta tendencia a lo ambiguo y a lo indeterminado reflejan una condición de crisis de nuestro tiempo; o bien, por el contrario, que esta poética, en armonía con la ciencia de hoy, expresa la posibilidad positiva de un hombre abierto a una renovación continua de los propios esquemas de vida y conocimiento, productivamente comprometido en un progreso de las propias facultades y de los propios horizontes. (Eco, [1962] 1985, p. 42)

Opuesta a la de Noé, la propuesta de Eco afirma que los modos en que los espectadores se enfrentan a la obra pueden estar predeterminados -en su misma ambigüedad- por los artistas, y sobre todo por los artistas contemporáneos. Sin embargo, a pesar de esa diferencia, ambos autores consideran la obra de arte como lugar en donde se manifiestan las estructuras profundas de los diferentes momentos históricos: el uno, en la manera en que los espectadores se relacionan con la obra; el otro, en el proceso del que se hace parte el artista al crear su obra; ambos apuntando al desorden, a lo indeterminado y al caos. Las consecuencias de estas similitudes y diferencias se trabajarán a profundidad en unos párrafos más adelante.

\section{CAOS, ANTIESTÉTICA Y MODERNIDAD}

Noé propone el "caos como estructura" después de reflexionar sobre el hecho de que la sociedad actual ya no tiene un centro que la unifique ni un orden intrínseco, como lo habrían tenido las sociedades medievales o renacentistas. La unidad de la concepción del mundo que existía previamente se ha disuelto, afirma Noé, y tal unidad y orden no deberían ya ser parte de las obras de arte de su momento histórico. Piensa Noé que cuestiones como la valoración positiva de la unidad de la obra de arte son rezagos del arte de otras épocas, en las que tal unidad se vivía realmente en la concepción del mundo que la sociedad asumía:

La unidad. He aquí un mito y un tabú. Nadie discute la necesidad de unidad en una obra (...)

El problema reside en que el concepto de unidad céntrica, antes retenida por el hombre ya no 
está retenida por él ni por nadie, pero subsiste como mero patrón, careciendo ya de todo sen-

tido. Ya no es natural la proyección de un orden a la obra del artista. (Noé, [1965] 1988, p. 195)

Noé plantea luego que el caos es la cualidad visible de esa época, y que tal cualidad no aparece traducida aún por el arte. El caos, según Noé, viene a ser un orden que aún no se entiende, un orden secreto: "O sea que el caos, el desorden, es en realidad un orden que no entendemos" (Noé, [1965] 1988, p. 198). Y ese caos es también una relación:

[Nuestra sociedad] Puede ser un todo. Un todo con elementos que tienen relación entre sí, una relación caótica pero relación al fin. Esta relación constituye una estructura, una estructura del caos. (Noé, [1965] 1988, p. 199)

La asociación entre las nociones de arte contemporáneo y desorden partía del hecho de que las estructuras de las diferentes facetas de la cultura occidental estaban cayendo -desde la filosofía y la ciencia hasta la psicología-, de manera que el orden establecido hasta el momento parecía perder validez, quedando de ello una caótica realidad. Para Eco, este desorden se expresa en el intento de los artistas por abrir conscientemente su obra a la ambigüedad y a la variedad de interpretaciones. Noé encuentra que, si bien gran parte del arte contemporáneo está buscando expresar ese desorden, en ningún lugar se ha asumido completamente el caos de la época. Afirma que aún sobreviven varios tabúes que el orden occidental anterior imponía sobre las ideas de lo que era una obra de arte.

En la escena argentina, estos cambios -incluyendo el manifestado en sistema de las artes- también se manifestaron claramente. Si desde finales de los años cincuenta y principios de los sesenta ya se podían apreciar los cambios dentro de la concepción moderna del arte, después de 1965 el cambio era innegable y ponía en crisis los conceptos sobre los que se basaba el relato del arte moderno. Por ejemplo -y como lo demuestra Andrea Giunta-, un representante de ese relato moderno en la escena argentina como fue Jorge Romero Brest, cuyas aspiraciones de internacionalizar el arte argentino estaban muy unidas a la idea de modernizarlo, se vio en aprietos a la hora de explicar y teorizar los cambios que desde mediados de los sesenta se vieron en la escena nacional e internacional ${ }^{2}$.

Si bien las propuestas de Noé no fueron las más extremas a nivel experimental y no se desligaron del todo del legado modernista ${ }^{1}$ - , es cierto que esta conmoción en el ámbito artístico también se manifestó en sus obras. Noé asume progresivamente en sus obras ciertos cambios que cuestionan la definición modernista de la pintura. Desde la Serie Federal en 1961 hasta la exposición en la galería Bonino de Nueva York en 1966, Noé hace un tránsito entre las incursiones anti-artísticas del informalismo, y los "desmadres" 3 que expone en Nueva York y que intentan reventar todos los conceptos modernistas sobre la pintura. En la trayectoria del artista, Antiestética podría pensarse como un puente entre lo que para Noé era el tenue caos del informalismo y un caos absoluto, un "desmadre".

\section{CÓDIGOS Y CAOS}

Romper con las normativas del lenguaje artístico del momento es para Noé uno de los requisitos que debe cumplir un artista que verdaderamente haga parte del proceso creativo de su momento histórico. Es precisamente allí donde incide la figura del caos. Por este motivo, resulta pertinente volver al concepto de desorden que Umberto Eco desarrolla en Obra abier- 
ta ([1962] 1985). Eco aborda la problemática de la innovación en el arte contemporáneo y su relación con el caos desde la teoría de la información, enfocándose, de nuevo, en el proceso interpretativo del espectador frente a la obra. A través de arduas argumentaciones que implican el uso de herramientas conceptuales de campos como la termodinámica, la teoría de la información y la semiótica, Eco propone una explicación para la variedad de significados que puede llegar a tener una obra de arte -y en especial una obra de arte contemporánea- y relaciona esta condición de la experiencia estética con la necesidad de romper los códigos viejos en los diferentes lenguajes artísticos.

Si todo lenguaje es considerado como una organización de signos y como una estructura con reglas específicas que facilitan la comunicación de los mensajes -si se consideran los lenguajes como sistemas ordenados- se podría llegar a la conclusión de que la inserción de desórdenes en la emisión de los mensajes iría en detrimento de las intenciones del emisor. Sin embargo -concluye Eco-, ciertos desórdenes e incumplimientos de las normativas que organizan el lenguaje resultarían en un aumento de la información que el mensaje comunica. Esto se debe a que, cuando los mensajes cumplen todas las normas del código y su significado es exacto, se convierten en mensajes previsibles. Pero la cantidad de información es inversamente proporcional a la previsibilidad de lo comunicado; por ejemplo, si el mensaje es: "mañana saldrá el sol" el mensaje es exacto, pero la información es muy escasa, pues todo el mundo sabe que el sol saldrá de nuevo. En cambio, si el mensaje es: "mañana hay un eclipse", la información es mayor, pues los eclipses son poco comunes. Pero si el mensaje fuera un poema sobre la salida del sol, la cantidad de información sería mucho mayor, pues a través de los imprevisibles usos del lenguaje del texto poético y de la inexactitud del significado se podría captar muchísimos más matices e insinuaciones, como la belleza de la luz o las emociones del comenzar el día, que no son expresables en el mensaje directo y correctamente enunciado.

En tal caso, en consecuencia, la información se asociaría no al orden, sino al desorden, por lo menos a cierto tipo de no-orden-habitual-previsible (...) la información dada por un mensaje organizado intencionalmente (mensaje poético o común) aparecerá solo como una forma particularísima de desorden: un desorden que resulta tal como parte de un orden prexistente. (Eco, [1962] 1985, p. 71)

El concepto de desorden es de primordial importancia en relación a un orden que Eco considera en esta argumentación, para entender de qué manera las posturas de Noé lo estaban llevando, como se verá más adelante, a un callejón sin salida.

Noé con su idea de asumir una actitud antiestética como forma de quebrar los códigos ya instalados, relaciona por contraste toda nueva propuesta con el arte que la precedía, procurando destruir sus preceptos. Sin embargo, lleva su planteamiento a límites peligrosos. Insiste en que el artista debe considerar la obra como parte de un proceso histórico creativo y no reparar más que en el proceso, olvidando así los resultados que se reflejen en la obra. Para Noé, la obra no vale en sí misma, sino como huella en un caminar de búsqueda creativa, y por ello es que le importa tan poco la claridad en el mensaje. De esta manera, plantea que la ruptura con los órdenes precedentes puede ser absoluta, haciendo a un lado la necesidad de que en la obra haya alusiones al pasado o a la tradición, es decir, al orden que el espectador conoce previamente al encuentro con la obra y que Eco consideraría necesario para que exista una posibilidad de comprensión de ese caos que se inserta. La búsqueda de un caos absoluto que 
rompa todos los códigos precedentes llevaría a que la obra sea completamente inentendible para el espectador.

La aventura se mide entonces por el destrozo. En ese destrozar hay unas ganas de hacer, pero la aventura consiste justamente en no saber a dónde se va. Sabiéndose de antemano no existe aventura. Entonces ¿dónde se puede hablar de orden como condición que debe cumplir la aventura? Por otra parte, ya desde el punto de vista del espectador ¿cómo puede apreciar este un orden que aún no conoce y está hecho en base de la destrucción de uno anterior? ¿No correrá el peligro de que lo tome por desorden? (Noé, [1965] 1988, p. 59)

Para Eco, no es cualquier desorden el que puede colmar de sentidos un mensaje: debe ser un desorden con respecto a un orden anterior y que se plantee a sí mismo como uno nuevo. Esto resulta obvio, pues cualquier aglomerado de palabras o frases caóticamente yuxtapuestas difícilmente transmitirán sentido alguno, de la misma manera en que es imposible que una mancha de pintura cualquiera nos transmita un mensaje. Es pues necesario, primero, que el desorden lo sea en relación a un orden precedente, que se inserte en una organización previa y que se compare con ella y, por último, que tal desorden plantee un orden nuevo, pues de lo contrario no tendría código y sería un caos inentendible, incapaz de transmitir.

El concepto de información ayuda a entender una tendencia en la que se mueve el discurso estético y en la cual intervienen además otros factores de organización; es decir, cualquier ruptura de la organización banal presupone un nuevo tipo de organización, que es desorden respecto de la organización precedente, pero es orden respecto de parámetros asumidos en el interior del nuevo discurso. (Eco, [1962] 1985, p. 71)

Eco afirma que el intérprete del mensaje, quien conoce el código anterior, puede leer el desorden planteado solo a través de ese conocimiento, es decir, que ese caos solo es significativo cuando se relaciona con ese orden conocido anteriormente. Así, el lector de tal mensaje -la obra contemporánea, por ejemplo- se mueve pendularmente entre la interpretación del código ya conocido y la decodificación de ese nuevo orden que, en comparación con el precedente, se presenta como caos.

Este movimiento pendular, necesario -según Eco- para que el desorden y el caos sean significativos en la obra de arte contemporánea, es lo que Noé niega, al separar tan tajantemente las concepciones entre el arte como búsqueda y el arte como resultado y al radicalizar la búsqueda de lo nuevo sin que el artista se sienta en la obligación de mantener, de alguna manera, el hilo que une a la obra con el espectador. Esta radicalidad, como se veía, no es expresada plásticamente en las obras anteriores a Antiestética. Incluso en las telas anteriores a 1965 el lazo con el espectador aún se conserva. Se trataría -según los parámetros de Eco- de un cierto desorden insertado sobre un código previamente conocido, y no de un 'verdadero' caos. En las obras posteriores, poco a poco los códigos conocidos son dejados de lado y las obras de Noé se convierten en 'desmadres', en instalaciones en las que los elementos constitutivos de la pintura llenan el espacio con su presencia, haciendo imposible encontrar un sentido más allá del que Noé mismo les da en su libro: obras que cobran significado únicamente para el artista y para aquellos que conocen su proceso creativo. Esta parece haber sido la vía específica que Noé siguió dentro del llamado proceso de 'desmaterialización' de la obra de arte y que una serie de artistas practicaron a partir de la segunda mitad de los años sesenta. 


\section{LA PINTURA Y EL CAOS}

En la Serie Federal, desarrollada durante 1961, se encontraba una atmósfera que unificaba cada tela. Sin embargo, la "visión quebrada" es una de las propuestas estéticas preponderantes que Noé expone en Antiestética y cuyos principios se ven en las obras fechadas después de la Serie Federal. Atento al 'caos' de la realidad circundante, decide renunciar a la necesidad de que en la obra se encuentre una unidad. Uno de los puntos álgidos de Antiestética es aquel que propone la búsqueda absoluta del caos, sin hacer referencia, necesariamente, a algún orden anterior. A la luz del análisis de Eco sobre la obra de arte contemporánea, la de Noé es una premisa que corre el grave riesgo de dejar a la obra en una isla de incomprensión por parte de los espectadores. Noé parece insinuar que la libertad del artista es tal que no debe preocuparse por insertar en su obra tales códigos y tampoco facilitar la comprensión del espectador. Sin embargo, como veremos en los próximos párrafos, el caos en las obras de este periodo (posteriores a 1961 y anteriores a 1965) sí se refiere a códigos establecidos con anterioridad.

En esos años, Noé empieza a quebrar la superficie de sus pinturas, ya sin envolverlas en una sola atmósfera sino incluyendo en ellas tensiones, divisiones y contraposiciones. El caos se manifiesta entonces como dualidad, falta de unidad y ruptura. En estas pinturas, Noé hace referencia al concepto mismo de cuadro y al código que presenta una estructura de madera con un lienzo adherido y cubierto con sustancias de diferentes colores y texturas como si fuera una obra de arte, incluyendo cuadros representados dentro de su cuadro. Es a este código al que Noé le inserta el 'desorden', para ponerlo en términos de Eco. La "visión quebrada" no solo rompe con el concepto de unidad en el cuadro, sino con el concepto mismo que se tiene del cuadro como obra de arte. Ya lo intuía Hugo Parpagnoli en un artículo de 1963 sobre el concurso del Instituto Torcuato di Tella -que Noé gana-:

Los cuadros de Noé son otra cosa. Resulta más cómodo mirarlos como una especie de monumentos que como pintura. Para acotar el hecho nuevo que proponen hay que recurrir a términos tales como escenografías, parques de diversiones, documentos plásticos o libros de historia natural. No son confortables. Tienen pocas concesiones al hábito visual que aún la pintura más audaz ha creado en la actualidad en los espectadores. Narran, expresan, discuten, simbolizan y representan. No pueden gustar a primera vista y tampoco pueden gustar después del mismo modo que gusta la pintura. La pintura queda, al lado de ellos, como el texto escrito de una obra de teatro. Los cuadros de Noé son la obra en escena. (Alonso, 1963, p. 3)

La obra fundamental para entender esta propuesta es Introducción a la esperanza (1963), con la que Noé ganó el mencionado Premio Nacional en 1963. Esta pintura se podría describir como la representación en clave neofigurativa de una manifestación peronista. En la parte baja, aparece una turba en un bastidor, en colores grises, representada con los rostros turbios y deformados de las otras figuraciones. En la parte superior, inscritos en varios bastidores más pequeños, aparecen carteles propios de una manifestación popular, como la bandera de Boca Juniors y arengas de clara alusión política o religiosa, pero deformados. Entre otros, aparece el rostro de Perón con la inscripción "El con el pueblo con Él", y un cartel en donde se lee "Cristo habla en el Luna Park." Es entonces una obra que consta de varios bastidores pintados, de diferentes tamaños, conectados a través de piezas de madera que al interior de la obra vendrían a ser los sostenes que los manifestantes usan para portar los estandartes. 
La fractura de la unidad es innegable. Resulta también innegable que Noé hace referencia a un cuadro perteneciente a la tradición del arte social -como Manifestación (1934) de Antonio Berni, aunque las diferencias en la forma de representar salten a la vista-. También hace referencia a la tradicional concepción de la pintura como una ventana hacia otro paisaje, introduciendo en ambas referencias ciertos cambios. El caos aún no es, como Noé parece proponer en su libro, tan radicalmente expuesto. Aún existen referencias que el espectador puede utilizar para leer, en esa obra, la manifestación popular y la referencia al peronismo. La radicalidad que se propone en Antiestética no era asumida aun en sus obras, y las aporías que plantea tal radicalidad están más o menos resueltas en ellas. Por ejemplo, en Introducción a la esperanza, si bien no hay un tratamiento directo del tema, tampoco parece ser problemática la cuestión de la función social del arte, por cuanto no problematiza la comunicabilidad de lo que expresa la obra, que de otro modo sí pone en duda Antiestética. Para Roberto Amigo,

En Introducción a la esperanza, la inclusión de la leyenda "Cristo habla en el Luna Park" y del peronismo obliga a una lectura crítica de la pintura como programa que debe dar cuenta del término "esperanza" que la denomina: es decir de la posibilidad de ascensión de las masas desde la materia hacia una instancia de liberación espiritual. (Amigo, 2005, p. 14)

Otra obra que trata el tema de la relación entre las masas y la pintura es Incendio en el Jockey Club (1963). Es un cuadro que representa un evento ocurrido en 1953, cuando una turba peronista incendia ese centro cultural de las élites, donde había varias pinturas de famosos maestros. De nuevo, la obra está divida en dos niveles: abajo, la turba enfurecida, también representada con los rostros deformados de las nuevas figuraciones; encima de ellos, la representación de las cuadros quemándose; envueltas en llamas se ven pequeñas pinturas, organizadas como una cuadrícula. Se contrapone el orden de las obras y el caos de la turba. Como señala Amigo (2005), esta contraposición sería unificada por el fuego, y la obra de Noé resultaría auto referencial: solo a través de la destrucción de los preconceptos de lo que debe ser una pintura, las obras de Noé podrían tener un lugar en el mundo del arte. En este sentido, el caos que Noé tanto busca articula cuestiones de lenguaje pictórico con la representación de las masas peronistas. Estos aparecen destruyendo los cuadros que representan ese viejo orden en el arte, de la misma manera que el caos que inserta Noé en sus obras destruye los viejos conceptos sobre lo que es una pintura. El caos, asociado entonces en las obras de este periodo a conceptos como federalismo, barbarie y peronismo adquiere un tinte político innegable. No quiere decir esto que Noé se considere peronista ni mucho menos federalista, pero sí indica una preocupación sobre la capacidad de la pintura de representar a las masas.

Así, en Incendio en el Jockey Club la posibilidad de dar una imagen a los menos favorecidos y de insertarla en el mundo del arte podría ser considerada como una propuesta que al tiempo cumple -como bien lo decía Andrea Giunta sobre Introducción a la esperanza ${ }^{4}$ los requisitos políticos y estéticos que Noé, como artista que se consideraba a sí mismo renovador de la escena porteña, podría exigir para su obra. En Incendio en el Jockey Club-como en la pintura sobre la marcha peronista- el caos no llega al paroxismo al que llegará en las obras posteriores a Antiestética, pues existen referencias claras al orden de la pintura que se quiere destruir y, por ello, la pintura aún tiene la posibilidad de comunicar. Sin embargo, al ser una obra auto referencial -en el sentido de que la masa iracunda que allí aparece es símbolo del caos que Noé busca como propuesta estética- también es una obra que propone su propia 
destrucción, pues su estructura resulta finalmente ser la misma de aquellas que serían destruidas por el fuego: un bastidor y un marco. En Introducción a la esperanza, la aparición de varios bastidores en una sola obra quiebra el concepto de unidad. En Incendio en el Jockey club, las pinturas que van a ser consumidas por el fuego -y la pintura donde están representadas- tienen como estructura un bastidor y un marco, creando así una auto referencialidad destructiva.

Hay otras obras en donde el bastidor deja de ser una estructura oculta para convertirse en un elemento plástico adicional. La primera de ellas es Mambo (1962), en la que un bastidor de revés aparece en la parte baja con la firma de Noé, el nombre de la obra y el año de realización. En la parte superior hay ciertas manchas de colores oscuros. Además, un extraño ser parece intentar trepar el bastidor de abajo para ingresar en el de arriba, sin pertenecer a ninguno de los dos bastidores. En obras posteriores, Noé encuentra nuevas posibilidades para este recurso plástico. Obras como Cristo (1963) o Cristo del pecado (1964) también utilizan la estructura de madera -tradicionalmente oculta- y la hacen visible. En ambas obras, las varas de madera que se cruzan en la estructura son expuestas al espectador y se convierten en los dos ejes del símbolo más importante del cristianismo: el bastidor de revés, evidenciado a través del rasgado del lienzo, se convierte en la cruz de Cristo.

Estas obras son estudiadas también por Amigo, quien relaciona la crisis de Noé cuando deja de pintar con la crisis que vivió como miembro activo de la iglesia católica: “La crisis personal con el catolicismo potenció su crisis sobre la pintura, tal vez no se pueda deslindar una de otra" (Amigo, 2005, p. 17) ${ }^{5}$. Así pues, de nuevo se encuentra en las obras de este porteño una estrecha relación entre los cambios estructurales al interior del cuadro y los cuestionamientos del artista frente a la realidad social de su entorno. Cristo, como símbolo del altruismo y de la acción en pro del necesitado, aparece cuando se destruye el lienzo. La figura del caos abre el espacio para que la posibilidad de una imagen que represente a las masas incursione en la obra.

Así como el bastidor cobra un significado importante en estas obras, también se encuentran telas en donde el elemento de la estructura básica que cobra significado plástico es el marco. Es a través del marco que Noé refiere a otras pinturas al interior de su obra. Al incorporar pequeños marcos adheridos a la tela, Noé puede reflexionar de manera plástica sobre el arte de la pintura. Este elemento, que se vio en Incendio en el Jockey Club, aparece también en obras como Vernisagge (1965) y Autorretrato (1963). En esta última se puede observar, en la tela, una gran cantidad de pequeñas obras enmarcadas, en una de las cuales se reconoce el rostro de Noé delineado con pocos trazos. La obra se convierte entonces en un retrato del retrato, en una representación de la representación. Vernisage, por su parte, representa la inauguración de una muestra de pinturas. De una manera similar a Incendio en el Jockey Club, en Vernisage se encuentran dos niveles en la tela: en la parte baja se encuentran los espectadores, con sus rostros deformes y, encima de ellos, las obras representadas con pequeños marcos más o menos organizados en una cuadrícula. Las figuras empiezan a salirse del marco y las pinturas de Noé empiezan a abandonar la estructura clásica de bastidor y marco, como si buscaran abandonar su condición de "ventanas perspectivas" que arrastraban desde el Renacimiento para ingresarse a la 'realidad'.

La inclusión de la cultura popular se manifiesta, en las obras de Noé, en la representación de las masas peronistas -más que en el trabajo con materiales no artísticos-. El paso de la preocupación por el lenguaje artístico a la preocupación por la realidad se dará en las obras que empiezan a salirse del marco y del bastidor, como si la pintura pareciera querer adueñarse 
del espacio de 'lo real', mientras las hordas peronistas invaden el lienzo con ira, descontrol y, sobre todo, caos. En este sentido, la inclusión de estas manifestaciones populares no solo inserta una imagen representativa del contexto político argentino en el medio artístico, sino que también se insertan en el quiebre del relato modernista que ocurría tanto en la escena local, como en la internacional. Si la ruptura de la estructura clásica de una pintura constituía una posibilidad de que se manifestara el caos -y con él las masas poco favorecidas- la salida de las figuras hacia la realidad era un nuevo paso en relación con las inquietudes de Noé en cuanto a la función social de su arte. A partir de Vernisagge (1965), la invasión de la realidad por parte de las figuras de los cuadros se hace cada vez más sorprendente y audaz, hasta el punto de que las obras de Noé se empiezan a convertir en 'desmadres' que ocupan el espacio con todos los elementos de la pintura, pero visiblemente 'caotizados'. Esto se evidencia más claramente en la exposición en la galería Bonino de Nueva York, en 1966. En esta exposición se encuentran varias obras que 'desarman' la estructura tradicional de la pintura -con sus bastidores, telas y oleos-, y muestran estos elementos siendo utilizados más allá del plano, invadiendo el espacio. Bastidores sin tela, inclinados en diferentes ángulos, salpicados de pintura, acompañados de representaciones de cuño neofigurativo, recortadas de su plano original y también insertadas de diferentes maneras en el espacio. En el montaje de la exposición, las obras se confundían unas con otras; algunas invadían el techo o se dispersaban por el piso. Entre estas obras estuvieron Así es la vida, señorita (1965) e Introducción al desmadre (1965).

\section{EL ESPECTADOR, 1965}

Antiestética es editada con la financiación de la Galería Van Riel, que ya había expuesto obras de Noé anteriormente. Si bien no es un texto académico, ni un ensayo largo, tampoco se podría asegurar que es un manifiesto artístico o un libro de crítica de arte. Antiestética es una publicación que tiene elementos de todo lo anterior y que también se nutre de la oralidad: según el testimonio de Noé en la entrevista concedida para este trabajo, el libro se inspira más en conversaciones con el grupo de la Otra Figuración que en algún autor específico. El libro está divido en diez capítulos, su tono tiende muchas veces a lo coloquial y a lo anecdótico, aunque también incluye argumentaciones complejas y narrativas particulares de la historia del arte.

El libro es presentado al público a finales de junio de 1965, día de la inauguración de la muestra Noé+experiencias colectivas, que reunió en el Museo de Arte Moderno de Buenos Aires a Aizenberg, Barilari, Deira, Maza, De la Vega, Blanco, Casariego, Carreira, Davila, Jacoby, Newbery, Perez Celis, Pablo Suárez y Wells. En el catálogo de esa exposición -una suerte de anti-catálogo-, Noé se dirige a los espectadores de la muestra en un texto escrito a mano alzada, con borraduras, tachones y algunos dibujos improvisados. El tono de tal presentación raya en la desfachatez:

Perdóneme, no tengo ganas de darle un catálogo. Me parece absolutamente inútil. Pero como usted se encontraría muy desconcertado sin un papelito en la mano, vaya esto para usted como mera aclaración. (Presentación, 1965)

Después de arremeter contra los críticos que lo han encasillado como neofigurativo y que confunden más al espectador con sus notas en los catálogos, Noé explica la intención de asumir el caos de la realidad a través de la disposición de obras de varios autores, de manera 
que el conjunto desordenado de tales trabajos individuales se convierta en una obra colectiva y tan caótica como la realidad misma.

En esta auto-presentación, Noé habla asimismo de su búsqueda y su creencia en el arte como una experiencia: "He invitado para esta experiencia a varios pintores (...) Creo ante todo en el arte como experiencia". Noé no es el único de la escena local del momento que asume su trabajo artístico como una experiencia. Una propuesta como La menesunda de Rubén Santantonín y Marta Minujín también es planteada en términos de experiencia. De hecho, este término acabó por ser determinante en las concepciones que Romero Brest asumía para entender el arte nuevo que empezaba a desarrollarse frente a sí:

El término experiencia, varias veces reiterado en su conferencia [sobre la obra de Minujín y Santantonín], pasaba a integrar, desde La Menesunda, la constelación discursiva que se definía en torno al problema de la vanguardia. La noción abría un campo infinito para el artista, ya que la experiencia no tenía límite alguno; era, por definición, el espacio por el que el arte se expandía. (Giunta, 2001, p.164)

La Menesunda, presentada en el mismo año que Antiestética, se asume como una experiencia para ser vivida por el espectador. En cambio -según se lee en el anti-catálogo-, Noé+experiencias colectivas sería una experiencia cuyo matiz apunta más hacia la intención de que sea vivida por los artistas que participan en ella.

En el plan de La Menesunda, el espectador es una de las principales preocupaciones a la hora de plantear la puesta en escena. El año anterior a la presentación de Antiestética, Julio Le Parc recibía un premio especial en la sección internacional del Premio Di Tella. En el catálogo del premio, este artista cinético afirmaba su búsqueda de un arte que incluyera la participación activa del público. Según Giunta:

El mensaje que el Di Tella enviaba al público era, con toda claridad, esto es lo mejor del arte joven argentino. Y lo mejor era, en este momento, lo que invadía el espacio íntimo del espectador, sus valores, su moral e, incluso, lo que comprometía su propio cuerpo. (Giunta, 2005, p.164)

El tema del rol del espectador en el arte nuevo era, pues, de principal importancia para muchos de los artistas que conformaban la movida artística del momento. Como se ve en la transcripción de la mesa redonda realizada en el Museo de Arte Moderno en julio de 1965, con el título "Nueva Actitud de los artistas" 6 , realizado después de la presentación de Antiestética y de La Menesunda y donde algunos artistas ${ }^{7}$ se reúnen a charlar entre ellos y con el público, el tema del espectador enciende los ánimos de manera evidente. Entre la aseveración de Noé según la cual el público "le importa un bledo", los reclamos a Minujín por parte de una señorita frente al desbarajuste que le parece La Menesunda y las reflexiones de los demás artistas alrededor de lo que se busca generar en el espectador, es posible apreciar la importancia atribuida al espectador. El hecho de que en ese mismo año Noé hubiera presentado un libro en el que afirmaba su radical desentendimiento del efecto de la obra en el espectador lo habría de colocar, entre sus colegas y frente al público, como un artista que independiza su quehacer artístico de varias condiciones que el medio exigía.

Sin embargo, más allá de las posturas que Noé adopta, lo cierto es que sus obras aunque sean realizadas desde el desinterés frente al espectador- siguen compartiendo un 
aspecto innegable con las propuestas exitosas de sus colegas: de la misma manera en que La Menesunda crea una ambientación en donde el espectador se ve envuelto, la muestra de Noé+experiencias colectivas abarca el espacio con su caos de imágenes yuxtapuestas. La exposición no era simplemente un conjunto de obras colgadas, sino más bien un desorden de telas colocadas a diestra y siniestra, envolviendo al espectador en un ambiente tan caotizado como "pictorizado", es decir, un ambiente invadido por pinturas de varios autores. Noé y sus colegas comparten el interés de que la realidad invada a la obra, y de que la obra se inserte en la realidad. Sin duda Noé no se interesó por la moda, la música o el baile en sus búsquedas como pintor, y las diferencias entre las dos exposiciones (la de Noé y la Menesunda) son notables. Sin embargo, al ver que sus pinturas invaden la realidad, y el caos de la realidad latinoamericana ingresa en sus obras, es innegable que el intento de sus colegas y el suyo propio comparten el interés por quebrar las fronteras entre vida y arte. O, como lo dicen Ana Longoni y Mariano Mestman:

El arte se extiende a los aspectos más diversos de la vida: la ropa, la música, el baile, las comunicaciones, y también la política. Aceptar como posible esta ampliación del arte no solo implica revolucionar los límites de lo que se considera arte, sino transformar las relaciones de los hombres con su entorno: la vanguardia proponía entonces una vida aumentada. (Longoni y Mestman, 2000, p. 47)

De todas maneras, para el caso de Noé, se requiere matizar este intento: Noé se inclina por resolver los dilemas del comercio entre vida y realidad al interior mismo de sus pinturas y despreciando la reacción del público.

Es muy significativo que, al radicalizar su búsqueda del 'caos', publique un libro donde hace explícitas sus propuestas plásticas. Si en sus obras Noé renuncia a la intención de que el público lo comprenda, en su libro pareciera querer aclarar sus propuestas. De hecho, buena parte de las interpretaciones que se han dado de la obra de este periodo -e incluso de gran parte de su obra posterior- parten de la interpretación que él mismo da en este libro. Pareciera que el progresivo abandono de los 'códigos' de la pintura y el avance del 'caos' sobre sus obras fueron de alguna manera compensados por una producción abundante de textos -informales, coloquiales y reflexivos- que resultan perfectamente comprensibles para cualquier lector, más allá de sus competencias en materia de arte y vanguardia.

\section{SUBDESARROLLO CULTURAL Y 'CAOS'}

Para Noé, el 'caos' es expresión de una sociedad latinoamericana que, aunque partícipe de la sociedad occidental, nunca se vio del todo incluida en sus ordenamientos. El artista latinoamericano tendría una ventaja a la hora de expresar ese 'caos' occidental contemporáneo, pues no tiene tantos tabúes encima como un occidental europeo, que le impedirían asumir ese desorden circundante: "Nosotros [los latinoamericanos] en cambio tenemos la barahúnda de datos aislados de realidades distintas. Tenemos el caos". (Noé, [1965] 1988, p. 185)

Hablábamos de cómo Occidente se niega a asumir el caos que ha planteado, pero aclará-

bamos que quienes realmente se niegan a asumir el caos son Europa y Estados Unidos, de acuerdo con lo que se manifiesta en el arte. Se lo reconoce al caos pero se habla de él en el idioma del orden. (...) ¿No será que le toca a otros países (pienso en los de América Latina) 
entrar a jugar en ese destino y que su papel sea fundamentalmente el de asumir ese caos?

(Noé, [1965] 1988, p. 178)

Noé otorga entonces al artista latinoamericano un papel específico en la historia del arte occidental: asumir el caos al interior de la obra. Sin embargo, debido al "subdesarrollo cultural", Noé afirma que la sociedad latinoamericana no ha hecho conciencia de su propio 'caos'; caos que resulta incomunicable al espectador. Noé, en varios apartes de su libro, hace referencia a la falta de desarrollo cultural en Latinoamérica. Este subdesarrollo cultural se convierte en uno de los enemigos principales del proceso creador genuino. Es un subdesarrollo que inventa prejuicios, impone normas y es 'formalista', en el sentido de dejarse atrapar por modas y estilos. Es un subdesarrollo, en últimas, que impide que la cultura pueda encontrar una imagen propia del lugar y del momento.

¿Qué nos impide la toma de conciencia de nuestro lugar? ¿Qué nos impide que asumamos con toda lucidez el papel que debemos jugar en el proceso internacional de la creación? La respuesta es simple: nuestro subdesarrollo cultural. Nuestro temor a dar pasos sin permiso de Europa. Ella es nuestra mamá y cuida de que no salgamos de casa sin permiso. Nuestra casa es Occidente para el caso. Culturalmente somos colonia, tenemos mentalidad de colonia. En otros órdenes también. ¿Es que podemos independizarnos culturalmente sin independizarnos en lo económico y lo político? (Noé, [1965] 1988, p.185)

Para un medio social culturalmente subdesarrollado, no regirse por las culturas a que si bien no pertenece tiene nostalgia de ellas constituye una traición. En lugar de entender la dinámica creadora de la libertad cultural quiere prefabricar esquemas extraídos de los hasta ahora hechos por esas culturas. (Noé, [1965] 1988, p. 27)

Noé hace énfasis en la necesidad de superar ese subdesarrollo cultural a toda costa. Aunque en algunos apartados confía en la posibilidad de que las vanguardias artísticas de la época puedan abrir un poco el espacio para una cultura menos atrasada, también hay fragmentos que llevan a pensar que el artista latinoamericano estaría en una fuerte encrucijada. Por un lado, Noé afirma que la creación de la imagen de una sociedad no puede ser asumida completamente como tarea del artista, pues en realidad es un proceso de la sociedad en su conjunto. Por otro lado, por su concepción de la dinámica del mundo del arte, como se veía párrafos atrás, Noé no cree que ese 'caos' -que él considera la imagen que la cultura latinoamericana puede brindar a la historia del arte occidental- pueda ser comunicado. Así pues, ¿qué salida tiene entonces el artista latinoamericano, si, al pertenecer a una sociedad subdesarrollada, no puede -según Noé- comunicar lo que individualmente encuentra ni expresar una verdadera imagen social? En una entrevista realizada por Rodrigo Alonso, Noé afirma que una de las razones por las que abandonó la pintura es que nadie pudo comprender su propuesta:

En el catálogo de esa exposición [Bonino, Nueva York, 1966] escribí un prólogo a la manera de una carta a mí mismo. Todavía no me daba cuenta, pero en ese prólogo me estaba despidiendo de la pintura. Era una carta del Noé crítico al Noé artista que le estaba diciendo que lo que hacía ya no tenía salida. Después de eso dejé de pintar. Un poco por una crisis personal, y otro poco porque nadie entendió mi propuesta. (Catálogo Imán: New York, p. 220)

Como se vio anteriormente, Roberto Amigo (2005) vincula la crisis de Noé frente a la religión católica con la crisis que experimentó en 1966, cuando dejó la pintura. Más allá de la 
relación entre estas dos angustias -como católico y como artista-, el artículo de Amigo no deja dudas sobre la existencia de una inquietud de Noé por su responsabilidad social frente a las masas, ya sea en el aspecto espiritual o en el político: "Noé propuso el mismo objetivo para el socialismo y el catolicismo: la concreción de la común esperanza del hombre, en lo material y en lo espiritual respectivamente, de superación de la burguesía" (Amigo, 2005 p.14).

Amigo termina concluyendo que:

Noé, en su período católico, comprendió que la religión no era simplemente los signos externos del culto, sino lo que ellos recrean y la pintura había parecido una herramienta apta. En los tiempos posconciliares, el artista había tratado de anular la escisión entre la esfera de lo político con la esfera de lo espiritual: solo el artista como aprendiz de brujo que revela lo oculto podía zanjar aquella escisión. Por eso Noé dirá que él no abandonó la pintura, sino que ella lo dejó: el arte no podía cumplir con la idea de "fusión" y "ascenso espiritual." Al artista solo le restaba poder disolverse en la vida social. (Amigo, 2005, p. 18)

Como se ha visto a través de estos párrafos, Noé siente un gran compromiso con su medio social, insiste en la posibilidad del arte como manifestación de la cultura y hace énfasis en el lugar de Latinoamérica en el desarrollo del arte contemporáneo. Pero también es extremo en sus concepciones sobre el arte como búsqueda y como huella del caminar del artista. Noé supone una barrera infranqueable entre lo que el artista genuino encuentra en su búsqueda y lo que en ella puede captar estando en una sociedad subdesarrollada como la latinoamericana. En su intento por asir el caos -elemento que internacionalizaría el arte latinoamericano-, Noé olvida que algún orden es necesario al interior de la obra para que la comunicación con el espectador no se vuelva imposible, como bien lo demostraba Eco en Obra Abierta y Ferrari en su reflexión sobre el arte de significado. Como dice Amigo (2005, p. 18), para Noé: "el arte no podía cumplir con la idea de "fusión" y de "ascenso espiritual." La salida que tendría el artista latinoamericano sería disolverse en la vida social poco a poco: Noé atendería un bar, politizaría sus propuestas y se dedicaría a la enseñanza de arte durante los nueve años que abandonó la pintura.

\section{NOTAS}

1 Ver Casanegra, Mercedes. Noé: el color y las artes plásticas. Buenos Aires: Alba, 1988.

2 Dice Giunta:

A diferencia de otros momentos, en los que Romero Brest tuvo la necesidad y el tiempo para explicar las transformaciones del arte contemporáneo, ahora carecía de ambos. Aunque en Buenos Aires el informalismo o exposiciones como Arte destructivo habían introducido elementos que desestabilizaban el modelo que había delineado para el arte del futuro, hasta 1963-1964 no dominaron expresiones similares a las que sacudían la escena neoyorquina. Por este motivo, a pesar de su desconcierto, no era crucial para este crítico tratar de explicar en qué consistían los cambios (...) A mediados de los sesenta el panorama se había transformado, y Romero Brest no podía ya mantener una posición prescindente. (2001, p. 168)

3 Este es el término que, en la entrevista realizada para esta tesis, Noé utiliza para describir las obras que expuso en la Bonino en Nueva York en 1966. 
4 Dice Giunta:

El cuadro era, prácticamente, la representación de una manifestación. Pero a la vez, también era un programa estético que condensaba, en una única imagen, las soluciones formales y los argumentos con los que Noé buscaba articular una respuesta ante un conjunto de requerimientos que provenían de la necesidad de una vanguardia local que considerara la realidad nacional y, también, la escena internacional.[...] Lo cierto es que Noé lograba introducir con esta pintura, premiada como un logro del joven arte argentino y como el signo de un desarrollo cultural, una estética que en los años del peronismo hubiese sido excluida de la alta cultura como populismo y propaganda. (Giunta, 2001, p. 203)

5 Dice Amigo:

En su práctica laica, Noé fue uno de los fundadores del efímero grupo católico "Convivencia", guiado por el sacerdote jesuita Joaquín Aduriz. Eran católicos reformistas que comenzaban a pensar el proceso de su inserción en la sociedad acorde con el "signo de los tiempos", laicos fuertemente preocupados por la relación entre catolicismo y política; sentían a la Iglesia alejada de los problemas reales del pueblo y a la sociedad descristianizada por el egoísmo inherente al sistema económico social. (2005, p. 14)

6 Véase: Amigo, Roberto, Silvia Dolinko y Cristina Rossi. Palabra de artista 1961-1981. Fondo Nacional de las Artes. Fundación Espigas. 2010.

7 Ernesto Deira, Armado Duarte, Kenneth Kemble, Florencio Méndez Casariego, Marta Minujín, Luís Felipe Noé y Pablo Suárez.

\section{REFERENCIAS}

AAVV. Catalogo Colección MNBA. Buenos Aires: Art Press, 2010.

Amigo, Roberto. Letanías en la catedral. Iconografía cristiana y política en la Argentina: Cristo obrero, Cristo guerrillero, Cristo desaparecido [En línea]. http://servidor.esteticas.unam.mx/edartedal/ PDF/Bahia/complets/AmigoLETANIAS.pdf (Acceso: 4 de mayo de 2013).

Alonso, Rodolfo, pról. Premio Internacional de Pintura Instituto Torcuato di Tella 1963. Buenos Aires: ITDT, 1963.

Alonso, Rodrigo. Imán: New York. Buenos Aires: Fundación Proa, 2010.

Amigo, Roberto, cur. Las armas de la pintura. Buenos Aires: Museo Nacional de Bellas Artes, 2008.

Amigo, Roberto, Silvia Dolinko y Cristina Rossi. Palabra de artista 1961-1981. Buenos Aires: Fondo Nacional de las Artes. Fundación Espigas, 2010.

Casanegra, Mercedes. Luis Felipe Noé: el color y las artes plásticas. Buenos Aires: Alba, 1988.

Casanegra, Mercedes, cur. Nueva Figuración. Deira, Macció, Noé, de la Vega. El estallido de la pintura. Buenos Aires: MNBA, 2010.

Castillo, Abelardo. Nueva figuración. Buenos Aires: Banco Velox, 2001.

Castillo, Abelardo. El mundo como representación. Historia cultural: entre práctica y representación. Barcelona: Gedisa, 1994.

Eco, Umberto. Obra Abierta. Barcelona: Planeta. 1985. (1962).

Giunta, Andrea. Vanguardia, internacionalismo y política. Arte argentino en los sesenta. Buenos Aires: Paidós, 2001.

Katzenstein, Inés, comp. Escritos de Vanguardia. Buenos Aires: Fundación Espigas, 2007.

Longoni, Ana y Mestman, Mariano. Del Di Tella a Tucumán Arde: vanguardia política y artística en el 68 aniversario. Buenos Aires: El Cielo por Asalto Ediciones, 2000.

Noé, Luis Felipe. Anarquía del año XX. Técnica mixta sobre tela 115 x 225. [En línea] 1961. www. luisfelipenoe.com (Acceso: 6 de enero de 2014).

Noé, Luis Felipe. Imagen Agónica de Dorrego. Técnica mixta sobre tela 130 x 97. [En línea] 1961. 
WWW.luisfelipenoe.com (Acceso: 6 de enero de 2014).

Noé, Luis Felipe. Mambo. Técnica mixta sobre tela 190x192. [En línea] 1961. www.luisfelipenoe. com (Acceso: 6 de enero de 2014).

Noé, Luis Felipe. jViva la santa federación! Técnica mixta sobre tela 130 x 97. [En línea] 1961. www. luisfelipenoe.com (Acceso: 6 de enero de 2014).

Noé, Luis Felipe. Autorretrato. Técnica mixta sobre tela 152x279. [En línea] 1963. www.luisfelipenoe. com (Acceso: 6 de enero de 2014).

Noé, Luis Felipe. Introducción a la esperanza. Técnica mixta sobre tela 195x197. [En línea] 1963. www.luisfelipenoe.com (Acceso: 6 de enero de 2014).

Noé, Luis Felipe. Cristo del pecado. Técnica mixta sobre tela 190x115. [En línea] 1963-64. Www. luisfelipenoe.com (Acceso: 6 de enero de 2014).

Noé, Luis Felipe. Así es la vida señorita. Instalación. [En línea] 1964. www.luisfelipenoe.com (Acceso: 6 de enero de 2014).

Noé, Luis Felipe. Introducción al desmadre. Instalación. [En línea] 1965. www.luisfelipenoe.com (Acceso: 6 de enero de 2014).

Noé, Luis Felipe. Noé+experiencias colectivas. Buenos Aires: Galería Van Riel, 1965.

Noé, Luis Felipe. Vernissage. Técnica mixta sobre tela y madera 218x250. [En línea] 1965. Www. luisfelipenoe.com (Acceso: 6 de enero de 2014).

Noé, Luis Felipe. Paintings. Nueva York: Galería Bonino, 1966.

Noé, Luís Felipe. Antiestética. Buenos Aires: Ediciones La Flor, 1988 [1965].

Noé, Luis Felipe. Pinturas 60-95. Buenos Aires: Museo Nacional de Bellas Artes, 1995.

Noé, Luís Felipe. Noescritos, Buenos Aires: Adriana Hidalgo Editorial, 2006.

Noé, Luis Felipe. Convocatoria a la barbarie. Técnica mixta sobre tela. 144 x 223. [En línea] 1961. www.luisfelipenoe.com (Acceso: 6 de enero de 2014).

Parpagnoli, Hugo. Luís Felipe Noé. Buenos Aires: Galería Bonino, 1961.

Vesprini, Mirta "Aproximación a la obra plástica de un neofigurativo argentino: Luis Felipe Noé". Manuscrito. Madrid: Universidad Complutense, 1992.

\section{Cómo citar este artículo:}

Lee, Juan. "Antiestética y la función social del caos en los años sesenta: Luis Felipe Noé como escritor y pintor". Cuadernos de Música, Artes Visuales y Artes Escénicas, 10 (1), 165-185, 2015. http://dx.doi.org/10.11144/Javeriana.mavae10-1.afsc 
